\title{
Typhoon/Hurricane/Tropical Cyclone Disasters: Prediction, Prevention and Mitigation
}

\author{
Defu Liu, Fengqing Wang \\ Disaster Prevention Research Institute, China Ocean University, Qingdao, China \\ Email: Liu@ouc.edu.cn,wfq@ouc.edu.cn
}

How to cite this paper: Liu, D. F., \& Wang, F. Q. (2019). Typhoon/Hurricane/Tropical Cyclone Disasters: Prediction, Prevention and Mitigation. Journal of Geoscience and Environment Protection, 7, 26-36. https://doi.org/10.4236/gep.2019.75003

Received: March 12, 2019

Accepted: May 14, 2019

Published: May 17, 2019

\begin{abstract}
Since 1972 Rita typhoon attacked on Dalian Port and induced severe catastrophe, we were studied on statistical prediction model of typhoon induced wave height and wind speed. With an increasing tendency of the natural hazards frequency and intensity, risk assessment of some design codes for coastal defence infrastructures should be of paramount importance influencing the economic development and a lot of lifes in China. Comparison between existing extreme statistical model like Gumbel, Weibull, P-III distribution or Probable Maximum Typhoon/Hurricane (PMT/PMH), Design Basis Flood (DBF) with our 1975-1980 proposed (CEVD) model showed that all the planned, designed and constructed coastal infrastructures accepted the traditional safety regulations are menaced by possibility of future typhoon/hurricane disasters and cannot satisfy the safety requirements with the increasing tendency of the extreme natural hazards. Our first publication in US (J. of Waterway Port Coastal \& Ocean Eng. ASCE, 1980, ww4) proposed an new model "Compound Extreme Value Distribution" used for China sea, after then the model was used in "Long term Distribution of Hurricane Characteristics” for Gulf of Mexico \& Atlantic coasts, U.S. (OTC.1982). 2005 hurricane Katrina, Rita and 2012 hurricane Sandy induced disasters proved 1982 CEVD and CEVD has been developed into Multivariate Compound Extreme Value Distribution (MCEVD). 2006 MCEVD predicted extreme hazards in New Orleans, Gulf of Mexico and Philadelphia areas. 2013 typhoon Fitow induced disaster in China also proved MCEVD 2006 predicted results.
\end{abstract}

\section{Keywords}

Typhoon/Hurricane Disasters: Probability Prediction Model, Design Code Calibration, Joint Probability Safety Assessment, Compound and Multivariate Extreme Value Distribution, Risk Assessment for Coastal, Offshore and NPP 


\section{Deadliest Typhoon/Hurricane/Tropical Cyclones in History}

The World Meteorological Organization estimates that about 90 percent of all natural disasters are extreme meteorological hazards like typhoon, hurricane and tropical cyclone triggered disasters in the Pacific, Atlantic, Indian Oceans, Caribbean, Gulf of Mexico areas. The 10 most severe tropical cyclone disasters in world history are shown in Table 1 and 2006 in China in Table 2.

In 2005, hurricane Katrina and Rita attacked coastal area of the USA, which caused deaths of about 1400 people and economical loss of $\$ 400$ billion in the city of New Orleans and destroyed more than 110 platforms in the Gulf of Mexico. In China, out of the total 28 provinces 10 coastal and 6 inland provinces are affected by typhoon induced disasters. In other words, more than 250 million lives are affected by typhoons, with an associated cost of approximately 60 trillion (RMB) GDP. In 2006, typhoon disasters were especially serious. Five of the most severe typhoon disasters brought about 1600 deaths and disappearances, and affected 66.6 million people. The economic loss reached 80 billion RMB and influenced agriculture areas totaling more than 2800 thousand hectares. Among these disasters, typhoon Saomai induced $3.76 \mathrm{~m}$ surges and $7 \mathrm{~m}$ waves, causing 240 deaths, sinking 952 ships, and damaging 1594 others in Shacheng harbor. If the typhoon Saomai had landed 2 hours later, then the simultaneous occurrence of the typhoon surge and high spring tide with $7 \mathrm{~m}$ wave would have inundated most areas of the Zhejiang and Fujian provinces, where located several NPP.

This paper discusses the joint probability analysis of meteorological, oceanographic and hydrological hazards based on our proposed Compound Extreme Value Distribution (CEVD) (Liu et al., 1980; Liu, 1982), Multivariate

Table 1. Deadliest tropical cyclones in history.

\begin{tabular}{ccccc}
\hline Rank & Name/Areas of Largest Loss & Year & Ocean Area & Deaths \\
\hline 1 & Great Bhola Cyclone, Bangladesh & 1970 & Bay of Bengal & 500,000 \\
2 & Hooghly River Cyclone, India and Bangladesh & 1737 & Bay of Bengal & 300,000 \\
3 & Haiphong Typhoon, Vietnam & 1881 & West Pacific & 300,000 \\
4 & Coringa, India & 1839 & Bay of Bengal & 300,000 \\
5 & Backerganj Cyclone, Bangladesh & 1584 & Bay of Bengal & 200,000 \\
6 & Great Backerganj Cyclone, Bangladesh & 1876 & Bay of Bengal & 200,000 \\
7 & Chittagong, Bangladesh & 1897 & Bay of Bengal & 175,000 \\
8 & Super Typhoon Nina, China & 1975 & West Pacific & 171,000 \\
9 & Cyclone 02B, Bangladesh & 1991 & Bay of Bengal & 140,000 \\
10 & Cyclone Nargis, Myanmar & 2008 & Bay of Bengal & 140,000 \\
\hline
\end{tabular}


Table 2. Details of the 2006 typhoon disaster in China

\begin{tabular}{|c|c|c|c|c|c|c|}
\hline $\begin{array}{l}\text { Typhoon } \\
\text { name }\end{array}$ & $\begin{array}{l}\text { Maximum } \\
\text { wind }(\mathrm{m} / \mathrm{s})\end{array}$ & Affected provinces & $\begin{array}{c}\text { Affected agriculture } \\
\text { area } \\
(1000 \mathrm{ha})\end{array}$ & $\begin{array}{l}\text { Affected population } \\
\qquad \text { (million) }\end{array}$ & $\begin{array}{c}\text { Death and lost } \\
\text { population }\end{array}$ & $\begin{array}{c}\text { Economic loss } \\
\text { (RMB) } \\
\text { (billion) }\end{array}$ \\
\hline Chanchu & 45 & Guangdong, Fujian, Zhejiang & 368.96 & 11.06 & 35 & 8.56 \\
\hline Bilis & 30 & $\begin{array}{l}\text { Fujian, Guangdong, } \\
\text { Hunan, Guangxi, } \\
\text { Zhejiang, Jiangxi }\end{array}$ & 1170.38 & 29.85 & 849 & 32.99 \\
\hline Kaemi & 40 & $\begin{array}{c}\text { Fujian, Guangdong, } \\
\text { Hunan, Guangxi, } \\
\text { Zhejiang, Jiangxi, Anhui, Hubei }\end{array}$ & 397.56 & 8.42 & 64 & 5.89 \\
\hline Prapiroon & 35 & Guangdong, Guangx, Hainan & 569.43 & 11.11 & 75 & 8.23 \\
\hline Saomai & 75.8 & $\begin{array}{l}\text { Fujiang, Zhejiang, } \\
\text { Jiangxi, Hubei }\end{array}$ & 223.16 & 5.99 & 570 & 19.49 \\
\hline
\end{tabular}

Compound Extreme Value Distribution (MCEVD), Double Layer Nested Multi-Objective Probability Model (DLNMOPM) (Liu 1989; Liu et al., 1993; Liu et al., 2000).

During the past 34 years since our CEVD firstly used to predict typhoon/hurricane extreme sea hazards in China, US Atlantic and Gulf of Mexico areas, 2005 hurricane Katrina, Rita and 2012 hurricane Sandy induced disasters proved 1982 CEVD and 2006 MCEVD predicted extreme hazards in New Orleans, Gulf of Mexico and Philadelphian areas, similarly, 2013 typhoon Fitow induced disaster in Shanghai area proved MCEVD and DLNMOPM 2004-2006 predicted results ( Liu et al., 2002; Liu et al., 2003; Liu et al., 2006; Liu et al., 2009a; Liu et al., 2009b; Liu et al., 2011; Liu et al., 2012; Liu et al., 2013; Liu et al., 2015a; Liu et al., 2015b).

Safety regulation for some NPP constructed coastal defense infrastructures located along East and South China Sea which recommended by China and IAEA (International Atomic Energy Agency) are much lower than 500 years return period typhoon induced sea hazards predicted by our proposed models (Liu et al., 2015c, Liu et al., 2016; Liu et al., 2017).

Another example is risk analysis of design flood for the Three Gorges Dam (TGD) the severest project in China, should be of paramount importance for about half of the population and Gross Domestic Product (GDP) in China (Liu et al., 2011). The design flood volume for constructed dam recommended by China design codes as 1000-year return period flood is lower than MCEVD predicted 100-year return period flood. A lot of constructed hydrological dams like TGD, Gezhouba dam designed by China safety regulations are menacing inland NPP. The MCEVD based joint probability prediction model of landslides and debris flows triggered by rainfall can be used as risk assessment for NPP around territories.

\section{Theory of Multivariate Compound Extreme Value Distribution (MCEVD)}

In 1972, Typhoon Rita attacked Dalian port in the North Bohai Bay of China, 
causing severe damage in this port. The authors found that, using traditional extrapolation (such as a Pearson type III model), it was difficult to determine the design return period for the extreme wave height induced by a typhoon. According to the randomness of annual typhoon occurrence frequency along different sea areas, it can be considered as a discrete random variable. Typhoon characteristics or typhoon-induced extreme sea events are continuous random variables. The Compound Extreme Value Distribution (CEVD) can then be derived by compounding a discrete distribution and the extreme distribution for typhoon-induced extreme events along China's coasts. Then the CEVD is used to analyze long-term characteristics of hurricanes along the Gulf of Mexico and the Atlantic US coasts. During the past few years, CEVD has been developed into MCEVD and applied to predict and prevent typhoon induced disasters for coastal areas, offshore structures, and estuarine cities. Both CEVD and MCEVD have the following advantages: instead of traditional annual maximum data sampling, the typhoon process maximum data sampling is used and the typhoon frequency is used in the models. In view of the "summary of flood frequency analysis in the United States" concluded that "the combination of the event-based and joint probability approaches promises to yield significantly improved descriptions of the probability laws of extraordinary floods. MCEVD is the model that follows the development direction of the extraordinary floods prediction, as desired by Kirby and Moss [Kirby \& Moss, 1987]. It stands to reason that MCEVD is a good model for typhoon (or hurricane) disaster prediction.

During the past years, CEVD and MCEVD have been applied to more than 40 coastal, offshore, and hydraulic projects in China and abroad (Langley \& El-Shaarawi, 1986; Kirby \& Moss, 1987; Naffa et al., 1991; Ochi, 1990; Quek \& Cheong, 1992; Resio, 2007). The theory of CEVD is also referenced by some foreign experts. Our proposed methods in are used as design criteria of wind-structure interaction experimentation for mitigating hurricane-induced U. S. coastal disasters.

The derivation of the MCEVD is as follows:

Let $N$ be a random variable (representing the number of storms in a given year), with their corresponding probability

$$
P\{N=k\}=p_{k}, \quad k=1,2, \cdots ;
$$

and

$$
\left(\xi_{11}, \ldots, \xi_{n 1}\right),\left(\xi_{12}, \ldots, \xi_{n 2}\right) \ldots \ldots
$$

be an independent sequence of independent identically distributed random vectors (representing the observed extreme sea environments in the sense defined above within the successive storms) with common density $g(\cdot)$. Then we are interested in the distribution of

$$
\left(X_{1}, \ldots, X_{n}\right)=\left(\xi_{1 i}, \ldots, \xi_{n i}\right)
$$

where $\xi_{1 i}$ is the maximum value of

$$
\xi_{1 j}, 1 \leq j \leq N, N=1,2, \ldots \ldots
$$


This represents the maximum annual value of the principal variable, together with the simultaneously occurring values of the concomitant variables. There is a reasonable approximation in definition of $\left(X_{1}, \ldots, X_{n}\right)$, no concerning of $\mathrm{N}=0$, because no extreme value of interest can occur outside the storm in case of $\mathrm{N}=$ 0 . The more detailed discussion of the model correction in case of $p(N=0)$ can be found in reference (Liu et al., 2013).

When multivariate continuous cumulative distribution is $G\left(x_{1}, \ldots, x_{n}\right)$, then we can derive the MCEVD as:

$$
F\left(x_{1}, \ldots, x_{n}\right)=\sum_{i=1}^{\infty} p_{i} \cdot i \cdot \int_{-\infty}^{x_{n}} \ldots \int_{-\infty}^{x_{1}} G_{1}^{i-1}(u) g\left(u_{1}, \ldots, u_{n}\right) d u_{1} \ldots d u_{n}
$$

where $G_{1}\left(u_{1}\right)$ is the marginal distribution of $G\left(x_{1}, \ldots, x_{n}\right) \quad g\left(u_{1}, \ldots u_{n}\right)$ is density function.

$$
\begin{aligned}
F(x, y, z) & =p_{0} Q(x, y, z)+\sum_{i=1}^{\infty} p_{i} \cdot i \cdot \int_{-\infty}^{z} \int_{-\infty}^{y} \int_{-\infty}^{x} G_{1}^{i-1}(u) g(u, v, w) d u d v d w \\
& =p_{0} Q(x, y, z)+\sum_{i=1}^{\infty} p_{i} \cdot i \cdot \int_{-\infty}^{z} \int_{-\infty}^{y} \int_{-\infty}^{x} G_{1}^{i-1}(u) g(u, v, w) d u d v d w+p_{0}-p_{0}(2)
\end{aligned}
$$

When the case of $\mathrm{n}=0$ is ignored, Equation (2) can be approximated as formula (3)

$$
F(x, y, z)=p_{0}+\sum_{i=1}^{\infty} p_{i} \cdot i \cdot \int_{-\infty}^{z} \int_{-\infty}^{y} \int_{-\infty}^{x} G_{1}^{i-1}(u) g(u, v, w) d u d v d w
$$

\section{Poisson-Gumbel Compound Extreme Value Distribution (P-G CEVD) and Its Applications}

When $G\left(x_{1}, \ldots, x_{n}\right)$ is probability distribution function of unit-variant random variable $\mathrm{x}$, then formula (1) can be simplified to

$$
F(x)=\sum_{i=0}^{\infty} p_{i}[G(x)]^{i}
$$

When typhoon occurrence frequency can be fitted to Poisson distribution, typhoon induced wave or wind fitted to Gumbel distribution, as formula (5)

$$
G(x)=e^{-e^{-x}}=\exp \{-\exp [-\alpha(x-\mu)]\}
$$

where $\alpha$ and $\mu$ as parameters of Gumbel distribution.

Then Poisson-Gumbel Compound Extreme Value Distribution (P-G CEVD) can be derived as

$$
F(x, y)=\sum_{i=0}^{\infty} p_{i}[G(x)]^{i}=\sum_{i=0}^{\infty} e^{-\lambda} \cdot \frac{\lambda^{i}}{i !}[G(x)]^{i}=e^{-\lambda[1-G(x)]}=1-P
$$

Typhoon induced extreme wave (wind speed) with return period $\mathrm{T}(1 / \mathrm{p})$ can be calculated by formula (7):

$$
H_{P}=\mu+X_{P} / \alpha
$$

where

$$
X_{P}=-\ln \left\{-\ln \left(1+\frac{\ln (1-P)}{\lambda}\right)\right\}
$$




$$
\lambda=\frac{n}{N}
$$

is the yearly mean value of typhoon frequency.

$\mathrm{N}$ is total number of year,

$\mathrm{n}$ is total typhoon number

$$
\left.\begin{array}{l}
\alpha=\sigma_{n} / S \\
\mu=\bar{H}-y_{n} / \alpha
\end{array}\right\}
$$

$\bar{H}, S$ : mean value and standard deviation of typhoon induced wave, $\sigma_{n}, y_{n}$ can be calculated by typhoon number.

Comparison between P-G CEVD, Gumbel and PIII-Distributions (Table 3)

\section{The Application of PNLTCED to Hurricane Katrina Disaster of New Orleans}

In this section the 55 year (1950-2004) measured data of hurricane winds, hurricane effect duration (provided by NOAA and Unisys Company) and the simultaneous Mississippi water level (provided by USACE) are used for the long term joint probability prediction of Hurricane Katrina. The value of wind speed, water level and wind duration are taken as variable series $x_{1}, x_{2}, x_{3}$, respectively. 1982 by CEVD predicted 100 years return period hurricane induced storm surge about 10 foot for Philadelphia areas which close to 2012 October 30, 08h:06 min. hurricane Sandy induced storm surge $10.62 \mathrm{ft}$ (dotted line in Fig 1),.but NOAA predicted surge only $7.52 \mathrm{ft}$.

\section{NOAA Proposed Unreasonable SPH/PMH and API Recommendations Induced Collapsing of 110 Fixed Platforms by 2005 Hurricane Katrina and Rita}

In 2005, hurricane Katrina and Rita destroyed more than 110 platforms in the Gulf of Mexico. There were many platforms with reported wave in deck (WID) damage, attributed to the crest of the large hurricane wave hitting the platform decks and causing major damage. P20 previous study of hurricanes Andrew, Lili and Ivan all reported destruction and major damage due to WID. The catastrophic failures and damage of platforms in GOM region show the deficiencies of API recommendations. Figure 2 and Table 4 that MCEVD predicted 100 years return values not only proved by 2005 hurricane Katrina, but also by 2012 hurricane Sandy.

Table 3 Relative differences of predicted return value $\Delta \mathrm{h}$ between three models.

\begin{tabular}{cccc}
\hline \multirow{2}{*}{ Model } & $100 \mathrm{a}$ & $50 \mathrm{a}$ & $20 \mathrm{a}$ \\
\cline { 2 - 4 } & $\Delta \mathrm{h}$ & $\Delta \mathrm{h}$ & $\Delta \mathrm{h}$ \\
\hline Gumbel & $26 \%$ & $25 \%$ & $23 \%$ \\
P III & $26 \%$ & $25 \%$ & $22 \%$ \\
P-Gumbel & $18 \%$ & $17 \%$ & $16 \%$ \\
\hline
\end{tabular}


Table 4. Comparison 100yr wind speed $(\mathrm{m} / \mathrm{s})$ for New Orleans and New Jersey zones.

\begin{tabular}{ccccc}
\hline Methods & MCEVD(2006) & $\begin{array}{l}\text { Coles \& Simiu } \\
(2003)\end{array}$ & $\begin{array}{c}\text { Casson \& Coles } \\
(2000)\end{array}$ & $\begin{array}{c}\text { Georgion \& } \\
\text { Davenport } \\
(1983)\end{array}$ \\
\hline $\begin{array}{c}\text { 100yr return value } \\
\text { for New Orleans } \\
\begin{array}{c}\text { 100yr return value } \\
\text { for New Jersey }\end{array}\end{array}$ & 70.0 & 46.0 & 38.0 & 39.0 \\
\hline
\end{tabular}

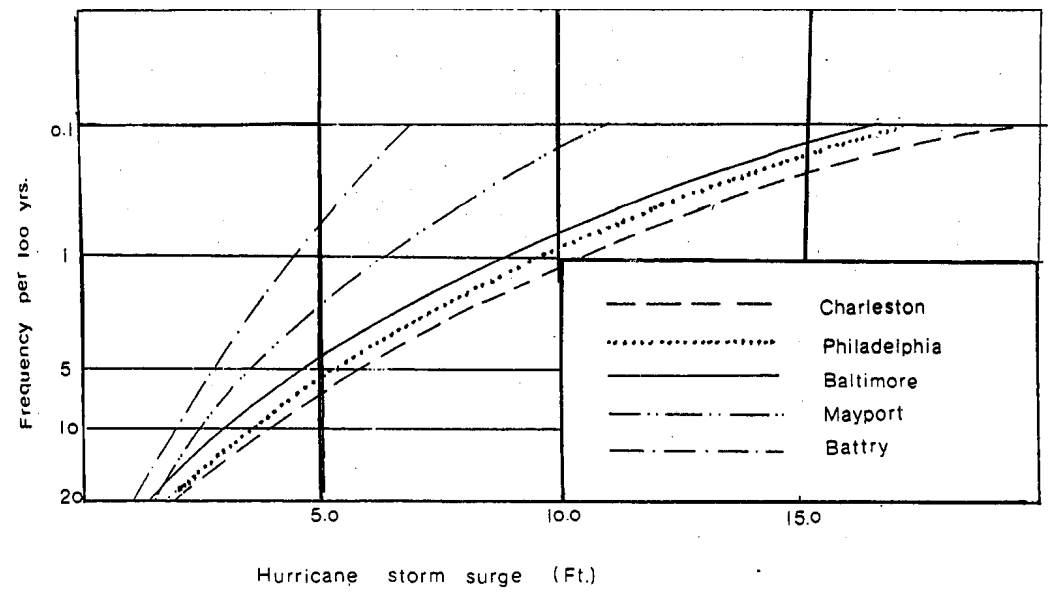

Figure 1. CEVD predicted hurricane storm surge along Atlantic coast.

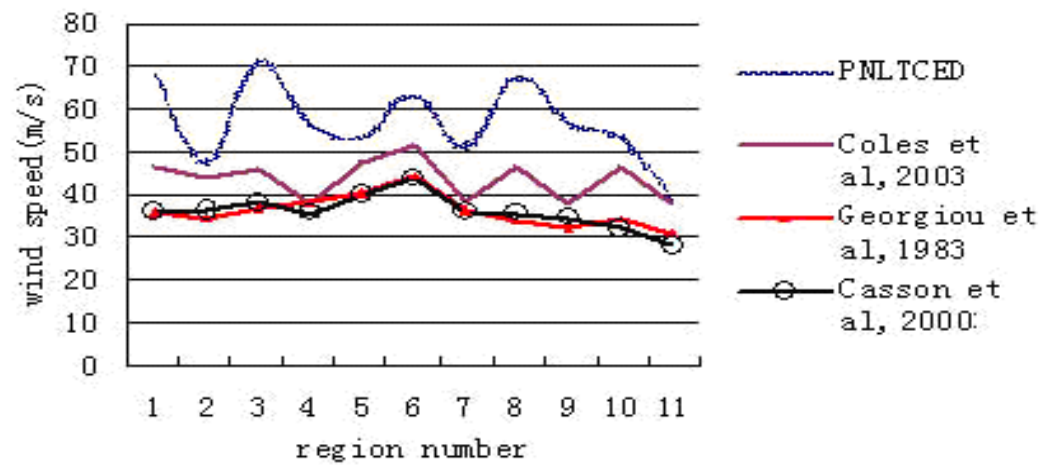

Figure 2. Comparison of $100 \mathrm{yr}$-hurricane wind speed using different methods.

\section{2013 Typhoon Fitow Proved 2006 MCEVD Predicted Disaster in Shanghai City}

Shanghai city locates at the estuarine area of the Yangtze River in China. Historical observed data shows that the typhoon induced storm surges, rainstorm flood coupled with the astronomical spring tide had threaten the security of Shanghai City. Based on the long term typhoon characteristics around Shanghai area, the Double layer nested multi-objective probability model was used to predict combined effect of storm surge, rainstorm flood and spring tide on the Shanghai city.

2013 typhoon Fitow induced significant losses in China. As shown in Table 5, that 2013 typhoon Fitow induced over warning water level in Yangtze River 5.15 $\mathrm{m}$, but China design code recommended 500 years return period warning water 
level in this area $4.80 \mathrm{~m}$, only corresponding to MCEVD predicted 50 year return value of combined effect of typhoon induced rain-storm flood ,storm surge with simultaneous astronomic tide.

Main reason of Hurricanes Katrina and Rita destroyed 116 fixed platforms in Gulf of Mexico.

The studies after Katrina and Rita in 2005 indicate that there are many platforms with reported wave in deck (WID) damage, due to the crest of the large hurricane wave hitting the platform decks and causing major damages. It implies that there are defects and deficiencies in conventional platform deck elevation design criteria recommended by API. The catastrophic failures and damage of platforms show the deficiencies of API recommendations. Based on the 20 years observed typhoon data in East China Sea and selects the significant wave height (Hs), concomitant surge and corresponding tide of each process as samples. Therefore, Hs, storm surge and tide are taken as variables in MCEVD for calculation of the deck height. The definition of water level see Figure 3, Figure 4 and Table 6.

\section{Risk Assessment for Safety Assessment for QS-NPP Defense Infrastructure Coastal Defense}

Risk assessment for NPP coastal defense is based on the ALARP principle. Joint

Table 5. Comparison between disaster prevention design criteria for Shanghai city.

\begin{tabular}{ccc}
\hline Model & Return period(a) & Design Value $(\mathrm{m})$ \\
\hline MCEVD & 100 & 5.89 \\
China Design Code & 50 & 5.10 \\
Shanghai Warning Water Level & 1000 & 5.86 \\
Typhoon Fitow observed water level & 500 & 4.80 \\
\hline
\end{tabular}

${ }^{*}$ Calculated by China design code.

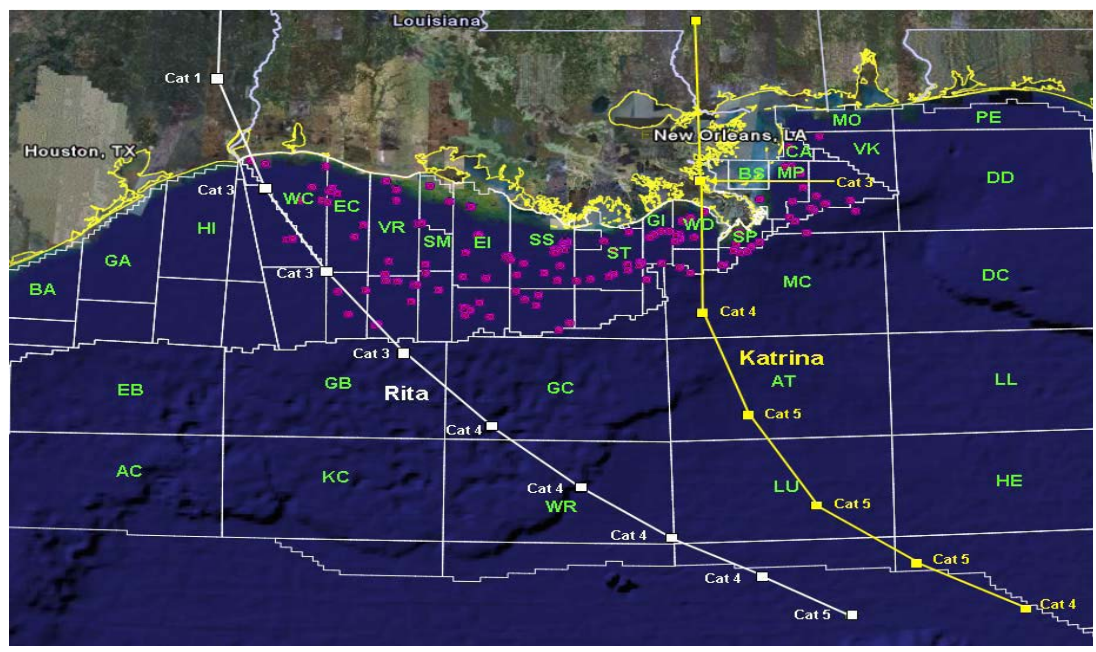

Figure 3. Hurricane Katrina and Rita destroyed and damaged 116 platforms. 
probability risk assessment for the above-mentioned two constructed nuclear power plants shows that the coastal defense infrastucture of both NPP cannot satisfy the $10^{-3}$ combined extreme external events risk according to the ALARP principle. This means that the risk to constructed Infrastucture is unacceptable

(Table 7).

\section{Conclusion}

The theory of MCEVD is based on the combination of typhoon process maxima data sampling and joint probability analysis of typhoon-induced extreme sea environments.

DLNMOPM is a theoretically based, applicable model for the prevention of

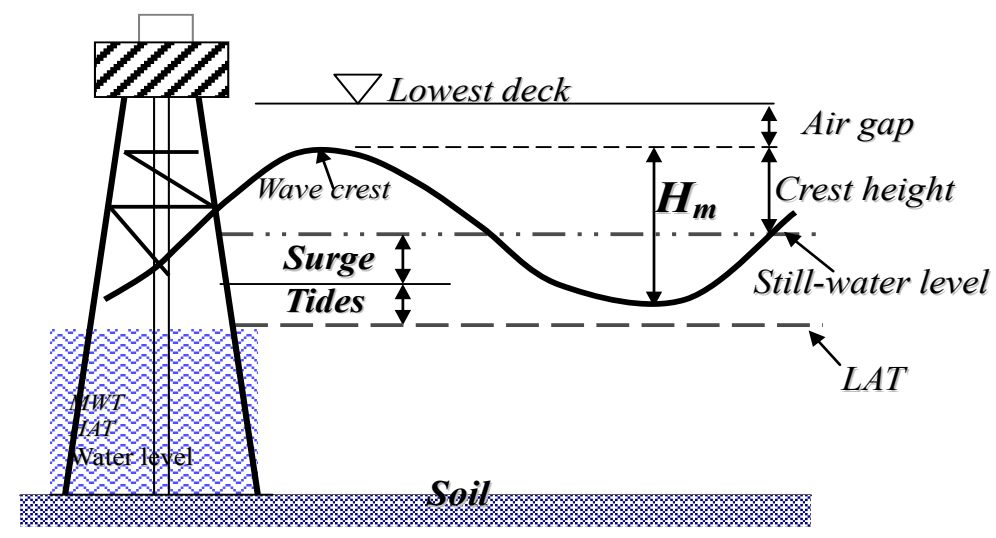

Figure 4. The definition of water levels and the lowest deck height. LAT-Lowest Astronomical Tide.

Table 6. Comparison between traditional method and MCEVD.

\begin{tabular}{cccccc}
\hline \multirow{2}{*}{$\begin{array}{c}\text { API } \\
\text { recommended } \\
\text { method }\end{array}$} & Hs $(\mathrm{m})$ & $\begin{array}{c}\text { Crest height with } \\
100 \text { return period } \\
\text { yrs }(\mathrm{m})\end{array}$ & $\begin{array}{c}\text { Surge with 100 } \\
\text { return period yrs } \\
(\mathrm{m})\end{array}$ & $\begin{array}{c}\text { Tide \& } \\
\text { Air gap }(\mathrm{m})\end{array}$ & $\begin{array}{c}\text { Deck elevation } \\
\text { above LAT }(\mathrm{m})\end{array}$ \\
\cline { 2 - 6 } & 5.56 & 6.78 & 1.23 & 11.96 \\
\hline \multicolumn{6}{c}{ Joint probability of 100-yera return period } \\
MCEVD & Hs (m) & Crest height (m) & Surge (m) & \\
method & 1. & 5.95 & 7.26 & 1.98 & 13.19 \\
& 2. & 5.62 & 6.86 & 2.10 & 12.91 \\
\hline
\end{tabular}

Table 7. Combined extreme external events with joint return period for QS NPP by PNLTCED.

\begin{tabular}{|c|c|c|c|}
\hline \begin{tabular}{|l} 
Extreme Event \\
Joint Probability
\end{tabular} & $\begin{array}{c}\text { Spring } \\
\text { Tide }(\mathrm{m})\end{array}$ & $\begin{array}{c}\text { Surge } \\
(\mathrm{m})\end{array}$ & $\begin{array}{c}\text { Wave } \\
(\mathrm{m})\end{array}$ \\
\hline 100 & 4.2 & 3.0 & 2.5 \\
\hline 500 & 5.0 & 3.5 & 3.0 \\
\hline 1000 & 5.5 & 4.0 & 3.5 \\
\hline 10000 & 6.5 & 4.8 & 4.0 \\
\hline
\end{tabular}


typhoon induced disasters. It can be widely used not only in coastal areas,offshore structures, and hydraulic engineering, but would also be helpful to governments as a scientific based measure in subsequent decision-making for disaster prevention and mitigation.

Design codes calibration of offshore, coastal and hydraulic infrastructures show that some traditional methods and models cannot support enough safety for very important infrastructures in global climate change conditions. The disasters induced by the 1975 typhoon Nina and 2005 hurricane Katrina give an important lesson: When natural hazards combined with human hubris, the natural hazards become a catastrophic disaster sooner or later.

\section{Conflicts of Interest}

The authors declare no conflicts of interest regarding the publication of this paper.

\section{References}

Casson, E., \& Coles, S. (2000). Simulation and Extremal Analysis of Hurricane Events. Appl. Statist, 49, 227-245. https://doi.org/10.1111/1467-9876.00189

Coles, S., \& Simiu, E. (2003). Estimating Uncertainty in the Extreme Value Analysis of Data Generated by a Hurricane Simulation Model. J. of Engineering Mech, 129, 1288-1294. https://doi.org/10.1061/(ASCE)0733-9399(2003)129:11(1288)

Georgiou, P. N., \& Davenport, A. G. (1983). Design Wind Speeds in Regions Dominated by Tropical Cyclones. Journal of Wind Engineering and Industrial Aerodynamics, 13, 139-152. https://doi.org/10.1016/0167-6105(83)90136-8

Kirby, W. H., \& Moss, M. E. (1987). Summary of Flood-Frequency Analysis in the United States. J Hydrology, 96, 5-14. https://doi.org/10.1016/0022-1694(87)90139-9

Langley, R. M., \& El-Shaarawi, A. H. (1986). On the Calculation of Extreme Wave Heights: A Review. Ocean Eng., 13, 93-118. https://doi.org/10.1016/0029-8018(86)90006-5

Liu, D. F. (1982). Long Term Distribution of Hurricane Characteristics. Proceedings Offshore Technology Conference, OTC 4325, Houston, USA, 305-313. https://doi.org/10.4043/4325-MS

Liu, D. F. (1989). Extreme Sea Environment Statistics in North Sea. NTNU Research Report Published. Trondheim, Norway: The Norwegian University of Science and Technology.

Liu, D. F., \& Dong, S. (2000). System Analysis of Disaster Prevention Design Criteria for Coastal and Estuarine Cities. China Ocean Engineering, 14, China Ocean Press.

Liu, D. F., \& Ma, F. S. (1980). Prediction of Extreme Wave Heights and Wind Velocities. Journal of the Waterway Port Coastal and Ocean Engineering, 106, 469-479.

Liu, D. F., \& Shi, J. G. (1993). The Joint Long-Term Distribution of Design Environmental Factors for Offshore Structures; Multivariable Probabilities and Simulating Method. Acta Oceanologica Sinica, 12, 465-474.

Liu, D. F., \& Wang, F. Q. (2009b). Prediction of Typhoon Triggered Sea Hazards in China. Proc. OCEANS'09, IEEE, 090204-001, Bremen, Germany.

Liu, D. F., \& Wang, F. Q. (2015a). Natural Hazards Crisis: Disaster Prediction, Mitigation and Prevention, Emerging Economies, Risk Intelligent Technology (pp. 129-136). 
London: Taylor \&Francis Group.

Liu, D. F., \& Wang, F. Q. (2015c). Risk Assessment for Nuclear Power Plants against Natural Disasters: Probability Prediction and Disaster Prevention Infrastructures (131 p). New York, USA: NOVA Publishers.

Liu, D. F., \& Wang, L. P. (2006). Theory of Multivariate Compound Extreme Value Distribution and Its Application to Extreme Sea State Prediction. Chinese Science Bulletin, 51, 2926-2930.

Liu, D. F., \& Wen, S. Q. (2002). Poisson-Gumbel Mixed Compound Distribution and Its Application. Chinese Science Bulletin, 47, 1901-1906.

Liu, D. F., \& Zhang, M. X. (2003). Stochastic Analysis Method of Sea Environment Simulated by Numerical Model. China Ocean Engineering, 17, 239-246.

Liu, D. F., Li, H. J., \& Wang, F. Q. (2013). Chapter 1. Typhoon/Hurricane/Tropical Cyclone Disasters: Prediction, Prevention and Mitigation. In Natural Disasters: Prevention, Risk Factors and Management (pp. 1-72). USA: NOVA Science Publishers, Inc.

Liu, D. F., Liu, G. L., \& Wang, F. Q. (2015b). Four Natural Disasters in US and China: A Evidence for Validity of Probability Prediction by Compound Extreme Value Distribution. 5th International Summit on Hurricanes and Climate Change.

Liu, D. F., Liu, G. L., \& Wang, F. Q. (2016). Risk Assessment for Nuclear Power Plants against Natura Disasters. Advances in Environmental and Agricultural Science, 408-423.

Liu, D. F., Liu, G. L., \& Wang, F. Q. (2017). Typhoon/Hurricane Disaster Prediction and Prevention for Coastal, Offshore and Nuclear Power Plan Infrastructure, In Hurricanes and Climate Change (pp. 135-166). Springer International Publishing. https://doi.org/10.1007/978-3-319-47594-3_6

Liu, D. F., Pang, L., \& Xie, B. T. (2009a). Typhoon Disaster in China: Prediction, Prevention and Mitigation. Natural Hazards, 49, 421-436.

https://doi.org/10.1007/s11069-008-9262-2

Liu, D. F., Xie, B. T., \& Li, H. J. (2011). Design Flood Volume of the Three Gorges Dam Project. Journal of Hydrologic Engineering, 16, 71-80. https://doi.org/10.1061/(ASCE)HE.1943-5584.0000287

Liu, G. L., Liu, D. F., \& Wang, F. Q. (2012). Risk Assessment Method for Offshore Structure Based on Global Sensitivity Analysis, Springer Netherlands. Modeling and Simulation in Engineering, Article ID: 671934. https://doi.org/10.1155/2012/671934

Naffa, M. G., Fanos, A. M., \& Elganainy, M. A. (1991). Characteristics of Waves off the Mediterranean Coast of Egypt. J Coast Res, 7, 665-676.

Ochi, M. K. (1990). Applied Probability and Stochastic Processes in Engineering and Physical Sciences (Chap. 6, pp. 111-133). New York: John Wiley \& Sons.

Quek, S. T., \& Cheong, H. F. (1992). Prediction of Extreme 3-sec. Gusts Accounting for Seasonal Effects. J. Structure Safety, 11, 121-129. https://doi.org/10.1016/0167-4730(92)90004-7

Resio, D. T. (2007). White Paper on Estimation Hurricane Inundation Probabilities (pp. 1-10). U.S. Army Corps of Engineering Report. 